\title{
Targeting resilience and profitability in African smallholder agriculture: Insights from ICRISAT-led research programs
}

\author{
Kai Mausch ${ }^{a \star}$, Alastair Orr ${ }^{\mathrm{a}}$, and B. Paige Miller \\ ${ }^{a}$ International Crops Research Institute for the Semi-Arid Tropics (ICRISAT), c/o The World \\ Agroforestry Center, ICRAF House, United Nations Avenue, Gigiri, P.O. Box 39063, Nairobi 00623, \\ Kenya; ${ }^{b}$ Department of Sociology, Criminology, and Anthropology, University of Wisconsin-River Falls, \\ 410 S. 3rd Street, River Falls, WI 54022, USA \\ *K.Mausch@cgiar.org
}

\begin{abstract}
We reviewed the strategy for Agricultural Research for Development (AR4D) adopted by the International Crops Research Institute for the Semi-Arid Tropics (ICRISAT). The objective was to examine ICRISAT's research strategy related to the twin challenges of resilience and profitability in developing technologies aimed at improving the livelihoods of smallholder farmers in the drylands of Africa. To do this, we examined the expected impact on resilience and profitability of its present program and the realized impact of ICRISAT's previous research. We argue that the current CGIAR Research Programs led by ICRISAT envisage separate product lines for resilience and profitability, targeted at two groups, i.e., subsistence- and market-oriented smallholders. This approach, expected to make technology more appropriate for farmers' needs, risks overlooking the interconnectedness of the two targets if they are too rigorously separated. Although our review of ICRISAT's previous research program suggests that success stories have taken numerous forms-some increasing resilience, others profitability-our review also suggests that it is possible to develop win-win technologies that improve both targets. Finding ways to replicate win-win technologies will require that ICRISAT tests the resulting technologies and their implementation in specific contexts to improve and replace them as the research programs evolve.
\end{abstract}

Key words: smallholder agriculture, dryland farming, resilience, profitability, development, ICRISAT

\section{Introduction}

Smallholder crop production in the dryland tropics faces twin challenges of resilience and profitability. On the one hand, smallholder agriculture must be resilient to shocks that threaten crop yields, household food security, and livelihoods. On the other hand, agriculture must also be profitable for smallholders with only small amounts to sell and who often live far from markets. These challenges are connected. Profitability requires crops that are resilient to biotic and abiotic stresses because markets require consistent supply. Similarly, smallholder farming systems must be resilient to price fluctuations so that volatile markets for food and cash crops do not threaten income and food security. In the coming years, several factors will make the need for a more profitable and resilient smallholder agriculture more pressing: growing populations will increase the demand for staple food crops (UN 2012); with changes in the geographic distribution of poverty, 
funding for agricultural research may increasingly shift to Africa (Chandy and Gertz 2011); a fastgrowing middle class is expected to create greater demand for more healthy and nutritious foods (Kharas 2010; Mubila and Aissa 2011); and rising income and more accessible markets will likely stimulate trade, providing opportunities for market-oriented small farmers. Recognizing the increasing relevance and connectedness of resilience and profitability for the livelihoods of smallholder farmers, it is important to understand the degree to which these needs are addressed in the processes and products of agricultural research.

We explore this issue by reviewing the strategy for Agricultural Research for Development (AR4D) adopted by the International Crops Research Institute for the Semi-Arid Tropics (ICRISAT). ICRISAT is one of 15 international agricultural research centers that are members of the CGIAR. ${ }^{1}$ ICRISAT addresses rural development in the semi-arid tropics (drylands) of sub-Saharan Africa (SSA) and India around its mandate crops: sorghum, millets (i.e., pearl millet and finger millet), groundnut, pigeon pea, and chickpea. Our assessment of ICRISAT's research strategy is based on the plan outlined in the CGIAR Research Programs (CRPs) for Dryland Cereals and Grain Legumes; the initiatives are led by ICRISAT and thus should most directly reflect its institutional approach.

The objectives of this paper were to examine how ICRISAT's research strategy has addressed the twin challenges of resilience and profitability. To do this, we

1. review the impact on resilience and profitability of its previous research program, focusing on 20 technologies developed over the last 45 years;

2. review the expected impact on resilience and profitability of its present research program, focusing on the 13 new agricultural product lines in the CRPs; and

3. assess the implications of this comparison for the current research strategy.

We argue that the approach to the twin challenges of resilience and profitability in the ICRISAT-led research program differs from that of its previous research program. The current CRPs led by ICRISAT envisage separate product lines for resilience and profitability, targeted at two separate groups of subsistence- and market-oriented smallholders. This is expected to make new technology more appropriate for farmers' needs. While perhaps useful for research purposes, there are a number of unintended, and potentially detrimental, consequences of this twin-track approach. Product lines for market-oriented farmers will still need to be resilient to shocks affecting crop yields. Product lines for subsistence farmers should focus not only on reducing vulnerability to crop loss but also on improving resilience at the household level by increasing profitability. This highlights the inherent connectedness of the two targets, which is at risk of being overlooked when they are too rigorously separated. Our review of ICRISAT's previous research program suggests that it is possible to develop win-win technologies that improve both resilience and profitability, often because farmers spot opportunities to combine both objectives. In addition, a focus on individual product lines differs from the approach taken by crop management scientists, in which the focus is on identifying combinations of technologies that will increase the resilience and profitability of the system as a whole, rather than of specific components. Although the twin-track approach may hold some promise, we argue that further thought is needed on the implications of this strategy

\footnotetext{
${ }^{1}$ The CGIAR describes itself as a "global research partnership for a food-secure future. CGIAR science is dedicated to reducing poverty, enhancing food and nutrition security, and improving natural resources and ecosystem services. Its research is carried out by 15 CGIAR centers" (see cgiar.org/about-us/).
} 
for resilience and profitability, and the extent to which ICRISAT can follow a win-win approach that targets both objectives simultaneously. ${ }^{2}$

The paper is organized into six sections. The next section develops a conceptual framework for ICRISAT's present research strategy based on the Dryland Cereals and Grain Legumes CRPs. ${ }^{3}$ Following this, we map the present research strategy in terms of its expected impact on resilience and profitability, based on the 13 agricultural product lines, and the realized impact on resilience and profitability of 20 ICRISAT technologies that had notable success in terms of impacts (ICRISAT 2012). Next, we analyze the potential of focusing on win-win technologies that successfully combined resilience and profitability using three case studies. We then outline the implications of the twin-track approach and some of the implications for the impact pathway. The final section concludes with a discussion of the implications of this review for AR4D.

\section{Conceptual framework}

Figure 1 shows a simplified framework that brings together the main concepts discussed in this paper. We see ICRISAT's research outputs (which are aggregated in the CRPs to product lines) as determined by two factors. One is the set of factors driving demand for these product lines (demand drivers), which we classify into markets and shocks. The second is the set of actors who need this technology (smallholder diversity), whom we classify into market-oriented and subsistence-oriented farmers. The result is two streams of product lines, one with a stronger market orientation and emphasis on improving profitability, the other with a stronger subsistence orientation and emphasis on improving resilience. As noted above, this distinction cannot be absolute because profitability also requires resilience, whereas resilience is partly determined by cash incomes and therefore by profitability.

Implicit within this framework, innovations require an enabling institutional setting. The innovation systems framework, for instance, emphasizes the role of framework conditions (e.g., policy and trust), intermediaries (e.g., NGOs, farmer organizations, and manufacturers) that provide farmers with access to new technology, and the business system that supplies consumers with products and services (DFID 2007). Access to information and seeds are major adoption constraints for cereals and legumes, especially in remote dryland communities. As there is often no commercial incentive for the private sector in this context, social networks play an important role in providing farmers with access to new technology. Consequently, innovations for subsistence farmers require impact pathways that use farmers' organizations and other forms of social networks to promote adoption and achieve impact. In West and Central Africa (WCA), for example, farmers' organizations have tested improved sorghum varieties, multiplied certified seed, and used radio to provide farmers with information. The development, deployment, uptake, and outcomes of any new agricultural product, therefore, depend on the coordination of a diverse mix of actors, agencies, and demands.

To begin, it is important to understand how profitability and resilience are conceptualized because this inevitably impacts the development of product lines and ultimately the farmers who use them.

\footnotetext{
${ }^{2}$ In this paper, we do not provide recipes for making smallholder agriculture more profitable and resilient. Differences among ICRISAT regions and among the organization's five mandate crops mean the answer will be context-specific. Furthermore, our treatment of the issues is selective rather than exhaustive and attempts only to bring these ideas into sharper focus and to explore their implications for the research process.

${ }^{3}$ The components of the conceptual framework, the categorization of product lines by profitability and resilience, and the typology of market- and subsistence-oriented farmers can be found in the proposals submitted to the Fund Council in August 2012. The proposals are aviailable from icrisat.org/crp/CRP3.6_Dryland_ Cereals_15Aug12.pdf (ICRISAT and ICARDA 2012) and icrisat.org/crp/CRP3.5_Grain_Legumes_15Aug12.pdf (ICRISAT et al. 2012).
} 


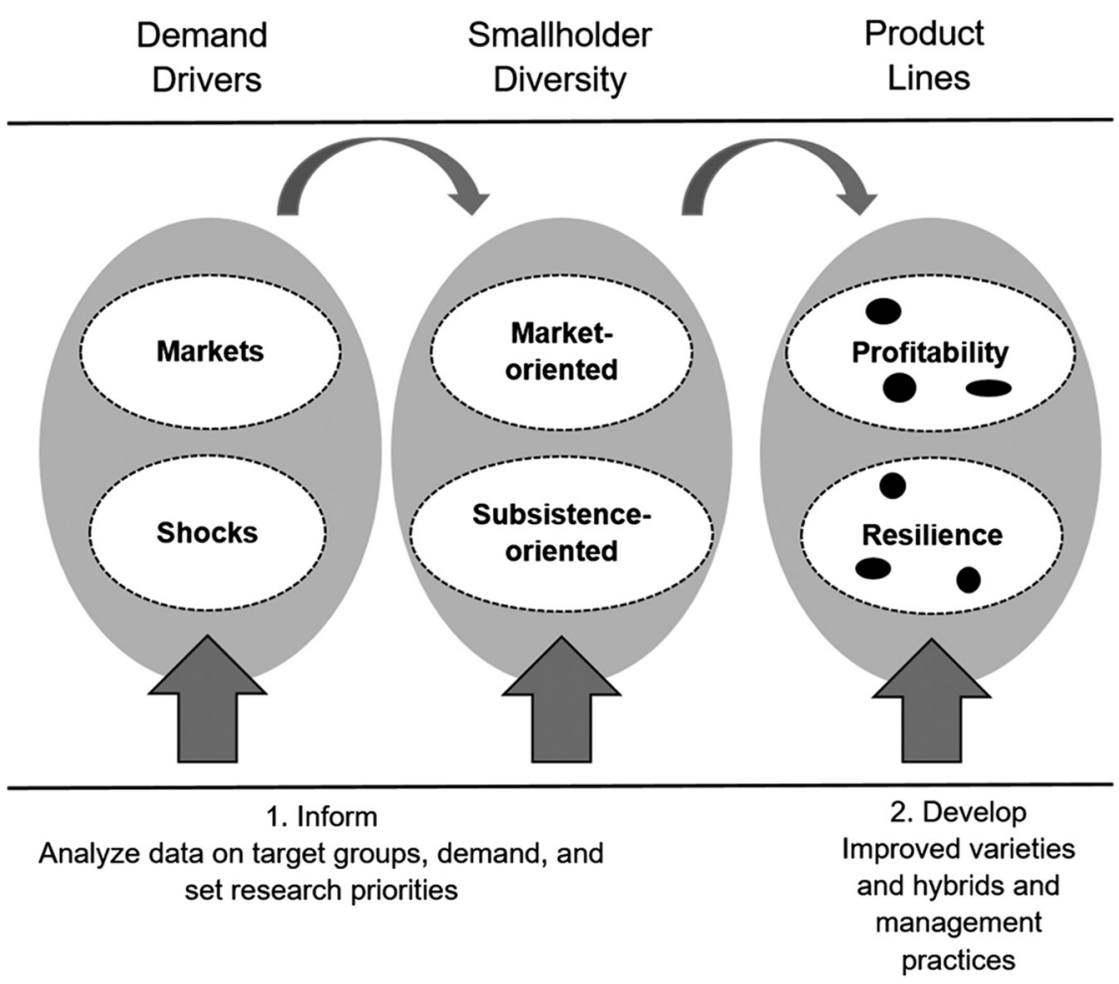

\section{Strategic Components}

Fig. 1. A simplified product development model.

Commercially, profitability is measured as the income left after deducting the cost of inputs including the opportunity cost of labour and management. For smallholder farmers, however, it is typical not to include the opportunity cost of land, family labour, or management in estimating total costs. Thus, what smallholders actually measure is not profitability but net returns. If we defined profitability in the same way as entrepreneurs, most smallholder crops would yield relatively low profits (Harris and Orr 2014).

However, resilience is used in distinct ways (it can refer to both reducing vulnerability to shocks as well as the ability to recover from shocks) and operates at several levels: crops, households, and farming systems (e.g., Walker et al. 2002; Alinovi et al. 2010; van Ginkel et al. 2013). The way resilience is defined and the level at which it is operationalized shapes the kinds of approaches that are likely to be effective. To reduce vulnerabilities to shocks at the household level, for example, research might better equip households to seize new market opportunities and invest in more profitable enterprises that will enable them to cope with shocks in the future because their higher level of assets reduces the danger of being pushed below the poverty line. Alternatively, if the aim is to enable households to recover from shocks, strategies to increase resilience might focus on income diversification-if one source of income fails, another takes its place. Other sources of resilience include social networks that provide support in cash or kind, access to loans, or insurance that allows households to recover quickly. Farming systems can be described as resilient if they contain a range of enterprises (crops and livestock) that enable them to recover quickly from shocks. AF van Rooyen, S Homann Kee-Tui, and P Masikati (unpublished data, 2013) defined resilience as the ability of a social-ecological system to recover from shocks, react to gradual change, and make 
use of opportunities. They adopt a Cup and Ball model and compare building resilience to moving a ball upwards over a series of gradients. At stage 1, the system is resilient but at a low level of profitability. Thus, resilience alone is not a desirable state. At stage 2, the system is at a higher level of profitability, but it is not necessarily resilient because the cup in which the ball rests is shallow. The ball can easily be dislodged and roll backwards to its starting point. With the above issues in mind, agricultural research needs to think of solutions that both deepen the cup and move the ball, i.e., increase profitability and at the same time build in resilience. In addition, rather than focusing on one definition of resilience or another, agricultural research should flexibly adopt the most appropriate approach for each context while being aware of possible implications for resilience at other levels.

\section{Comparing past and present research products}

We conducted a mapping exercise to determine whether product lines were primarily market oriented or subsistence oriented to get an overview of the extent to which the two goals are prioritized. We used the description of the product lines that are included in the CRP proposal documents ${ }^{4}$ as the basis for this. Market-oriented product lines were defined as those associated more with increases in profitability, whereas subsistence-oriented product lines were associated more with increases in resilience. The exercise was conducted for the 13 dryland cereals and grain legumes product lines (six for cereals and seven for legumes, excluding product lines under the leadership of other CGIAR centers involved in these programs). Scoring was not intended to reach a definitive judgment about the precise nature of each product line. Rather, the objective was to focus attention on what specific product lines are for in terms of development outcomes (profitability and (or) resilience) and for whom they are developed (market- or subsistence-oriented farmers).

All 13 product lines focus on crop improvement, with the importance of crop management recognized by articulating each product line as an integrated technology package that included improved management practices. Although the CRPs recognized that product lines are more than just improved varieties, the crop management practices appropriate for each product line were not specified. Using the written description of the most important anticipated impacts of each product line found in the CRP proposals, we scored the 13 crops on a 1-4 scale. Values closer to 1 indicate low profitability/ resilience and values closer to 4 indicate high profitability/resilience. ${ }^{5}$

Figure 2 shows the score results. All 13 product lines fall into the two high-low quadrants. Three product lines score high potential impacts on resilience, but low changes in profitability are expected. For example, heat tolerant chickpea was scored high on resilience but low on profitability because the product was explicitly designed to address the potential reduction in chickpea yields due to climate change, but no mention of profitability impacts was made in the product description, even though reduced losses would increase profits. In contrast, 10 product lines have high potential impact on profitability but low expected change in resilience. Two clear examples of such products are (1) herbicide-tolerant, machine-harvestable chickpea varieties and (2) hybrid pigeon pea varieties. The former was explicitly developed to increase profits by addressing harvesting delays and decreasing the costs of hiring labour, whereas the latter addresses increasing profits through an increase in yields via direct investments. All product lines were scored on their primary stated

\footnotetext{
${ }^{4}$ The documents are publicly available from icrisat.org/crp/CRP3.6_Dryland_Cereals_15Aug12.pdf (ICRISAT and ICARDA 2012) and icrisat.org/crp/CRP3.5_Grain_Legumes_15Aug12.pdf (ICRISAT et al. 2012).

${ }^{5}$ Additional details on the rankings of the 13 product lines and the 20 success stories (discussed at more length below) can be found in the working paper (Orr and Mausch 2014; oar.icrisat.org/8623/).
} 


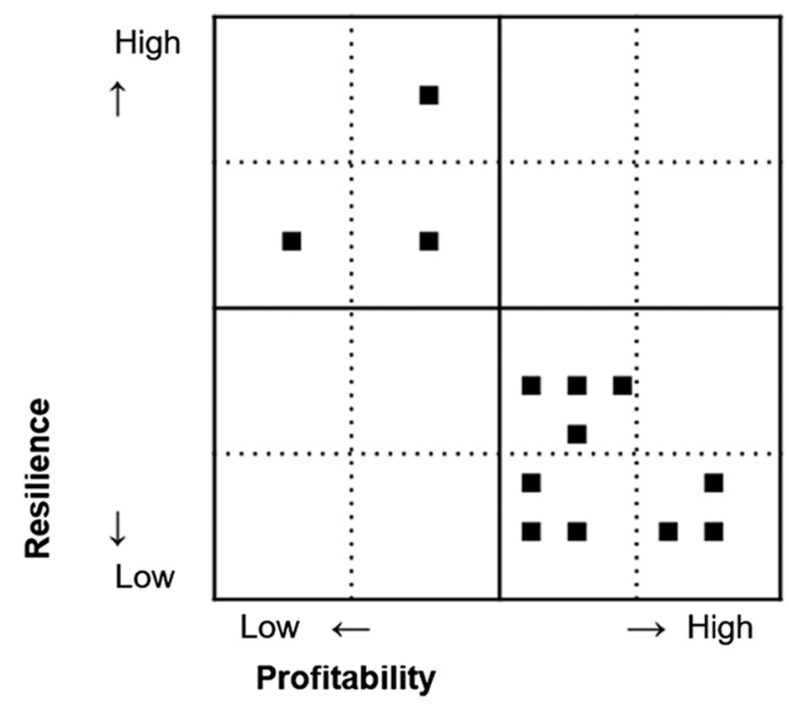

Fig. 2. Cereal and legume product lines mapped by potential impacts on profitability and resilience.

target, not including the detailed management practices and accompanying technologies that are included in the design. Although most product lines focus on variety development, all product lines also include farming practices and systems improvements in their secondary targets. None of the products' primary targets were determined to have high potential impact on both profitability and resilience. $^{6}$

Scoring product lines in this way can only be approximate, and the results should be seen as illustrative. These results suggest that ICRISAT is moving towards a twin-track approach that identifies product lines for different target groups. ${ }^{7}$ It also indicates that the market-oriented farmers are prioritized because more than $75 \%$ of the product lines are targeting that group.

To gain insights into whether or not the twin-track approach has been evolving from institutional lessons learned at ICRISAT, we further analyzed past success stories. ICRISAT identified its success stories as research products that have achieved significant and measurable impacts, drawing mainly on the publication "Jewels of ICRISAT" (ICRISAT 2012). Furthermore, some case studies were selected as success stories based on a brainstorming session of the Markets, Institutions and Policy group of ICRISAT. Twenty success stories were identified, which were then ranked on a 1-4 scale for each criterion following the same method as for the 13 CRP product lines. ${ }^{8}$ As with product lines, scoring success stories in this way can only be approximate, and the results should be seen as illustrative.

\footnotetext{
${ }^{6}$ To check the reliability of our scoring, we requested that the coordinators for the 13 product lines also provide scores using the same technique described above. Although only five responded to the request, our scoring closely matches that of the product line coordinators. Comparing our original scores with those given by the five product line coordinators resulted in only two small revisions. For one product line, the profitability score was lowered by one, and in another case, the resilience score was increased by one. This overlap suggests that, although our scores are subjective, they are not arbitrary.

${ }^{7}$ This distinction is not absolute. Profitable product lines have to be resilient too, to reduce risks for marketoriented farmers. In practice, therefore, some product lines may combine both profitability and resilience. In contrast, resilient product lines do not necessarily have to be profitable.
}

${ }^{8}$ See Orr and Mausch (2014). 


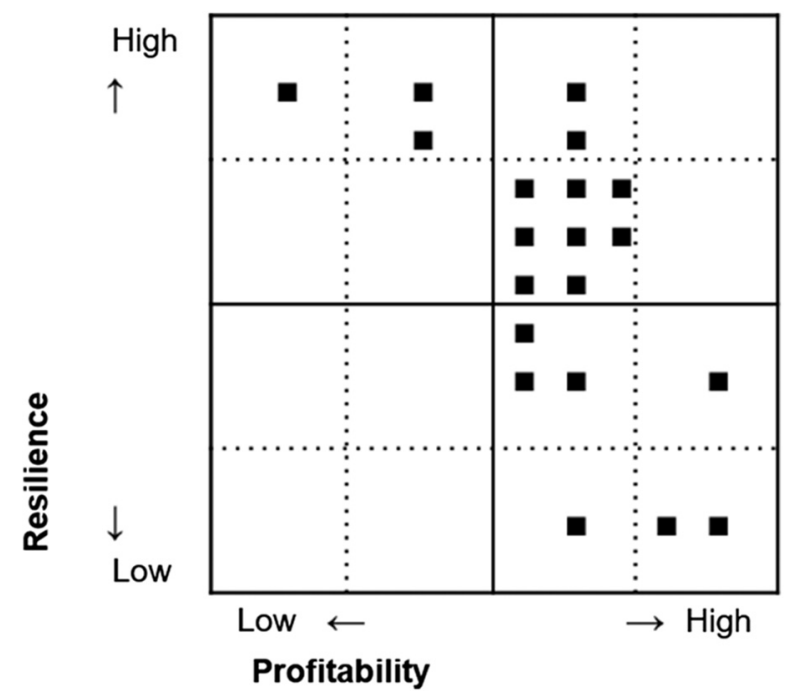

Fig. 3. ICRISAT success stories mapped by profitability-resilience orientation.

Figure 3 shows that, of the 20 success stories,

- $13(65 \%)$ had high impact on resilience;

- $17(85 \%)$ had a high impact on profitability;

- $\quad$ and $10(50 \%)$ significantly increased both resilience and profitability.

In spite of ICRISAT's current emphasis on profitability and thereby markets, Fig. 3 suggests that, in terms of overall impact, its success stories have been more or less balanced between increasing profitability and increasing resilience, with a slightly better track record for increasing profitability. However, it appears difficult to have high impacts on profitability and resilience at the same time. Only $50 \%$ of the success stories represent win-win cases.

\section{Why not focus on creating win-win products?}

What lessons should be drawn from this review of ICRISAT's past research programs? On the one hand, one could argue that the recipe for success is not necessarily to combine resilience and profitability but to look for opportunities that can enhance either of them. On the other hand, one could suggest that win-win cases are clearly possible. If half of these stories are win-win stories, why should ICRISAT and others not aspire to replicate them? To investigate this, in the next section, we illustrate three case studies within this win-win category.

The first case study comes from Andhra Pradesh in India. Short-duration cultivars released in 1999 have been widely adopted in the state (Bantilan et al. 2014), increasing a typical farm household's yield of chickpea. As a result, the acreage planted with chickpea in the state increased 10-fold between 1990 and 2010. Why this success? First, the new cultivars are resistant to Fusarium wilt, thus, reducing the risk of crop loss. Second, they are short-duration cultivars, reducing the risk of yield loss from drought. Third, they are profitable because they require less labour than cereals, planting is easily mechanized, they have a ready market, and they fetch high prices. Thus, success reflects the combination of market drivers with improved technology that improves profitability and resilience. 
The second case study ${ }^{9}$ in Mali stems from the Integrated Striga and Soil Fertility Management (ISSFM) strategy for pearl millet and sorghum. This strategy targets the parasitic weed Striga hermonthica, which is found on half the fields planted with sorghum and pearl millet in the Sahelian and Sudanian zones of West Africa. On the 20\% of fields with high levels of infestation, Striga can result in loss of up to half the yield of these staple food crops. The ISSFM combines several interventions such as intercropping with cowpea or groundnut, micro-dosing fertilizer at sowing and at 4-6 weeks after planting, manuring with compost, and hand-pulling Striga when it flowers, as well as the use of an improved variety that is resistant or tolerant to Striga. Evaluation with Farmer Field Schools in Mali showed that the benefits from ISSFM were up to seven times higher than the benefits from farmers' normal practice. Although the costs of ISSFM (excluding the cost of labour) were twice the cost of farmers' normal practice, the benefits exceeded costs by a ratio of 2:1. The main benefits came from the additional grain and fodder from the cowpea or groundnut intercrops, rather than increased yields of the cereal crop. These gave farmers a profitable product line in the form of cash income. What are the lessons? First, the product line was clearly designed to improve resilience and household food security. Second, researchers worked closely with farmers to fine tune and evaluate the technology in agronomic and economic terms. Third, the resilient product line also provided farmers with a profitable product line (intercrops) that generated cash income and assisted the transition from subsistence- to market-oriented farming.

Finally, the third case study ${ }^{10}$ in Zimbabwe, where goats are a major source of income, involves a set of interventions that allowed smallholders to keep more goats, earn more income from goat sales, and spend more on inputs to boost yields of staple food crops. Interventions included the introduction of fodder crops that increased the supply of goat feed, veterinary services that reduced goat mortality, and regular goat auctions that increased prices, made pricing more transparent, and allowed sales throughout the year. A small tax on each goat sold helps maintain the auctions, and private buyers purchase goats and sell fertilizer and vaccines. Households that have adopted these innovations have seen their income from goats double in four years. Models project a potential for over three times the income growth, from $\$ 89$ to $\$ 302$ USD per year, reaching $\$ 400$ USD per year when buyers pay for higher quality goats. Why the success? First, the innovation platform approach was able to unblock a market bottleneck that required coordinated action by key stakeholders. Second, the innovations were market oriented, which allowed smallholders to profit from the growing demand for goat meat in nearby Bulawayo. Third, the innovations improved resilience at the household level, because increased cash income could be used to reduce vulnerability to drought or illness, and enhance education.

These success stories suggest that win-win product lines often emerge in a two-step process as farmers innovate and researchers learn (Fig. 4). In summary, we learned that for Striga management in WCA researchers use legume intercrops to suppress Striga and improve resilience. When the technology was rolled out and farmers experimented with it, they realized the secondary opportunity and sold legumes to increase their profits. Similarly, researchers in East and southern Africa trying to increase profits from goat production did not foresee that the profits would be used to increase resilience by, for example, investing in fertilizer for maize. In all cases, researchers did not set out to create a win-win product line. Instead, the product line developed in unpredictable ways. The message is that win-win product lines can evolve through a process of adaptation and discovery. Given the iterative nature by which win-win products have emerged, there is nothing to preclude the 13 new product lines from ultimately becoming technologies that contribute to both resilience and profitability. In order for this to occur, however, it is important to track farmers' actual use of new technologies and

\footnotetext{
${ }^{9}$ Summarized by T van Mourik, E Weltzien, and S Traore (unpublished data, 2013).

${ }^{10}$ Summarized by A van Rooyen and S Homann Kee-Tui (unpublished data, 2014).
} 


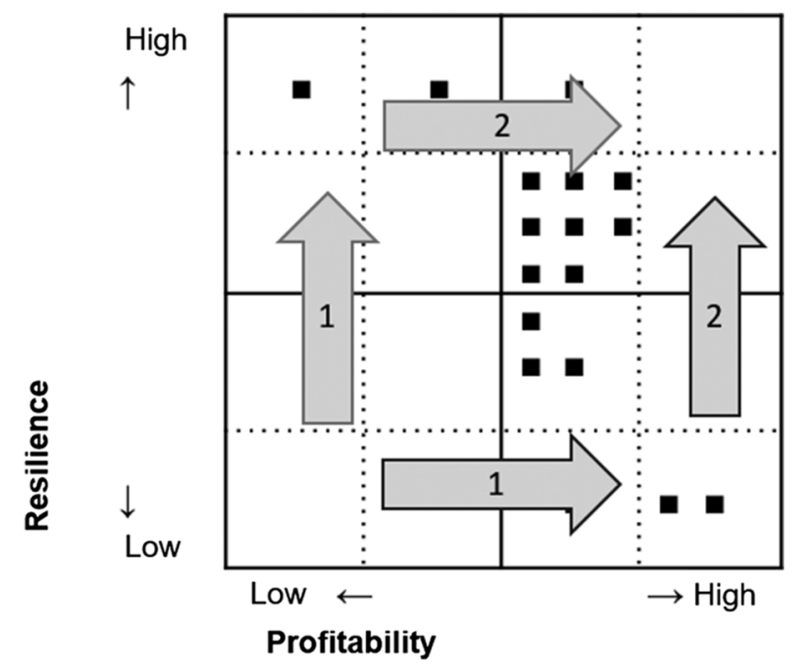

Fig. 4. Win-win product lines as a two-step process.

adopt a flexible implementation process to meet their evolving needs. This, in turn, necessitates communication and feedback loops among smallholder farmers, researchers, and other actors, both public and private, to avoid an overly rigid separation of the two pathways in the deployment of the 13 lines. Indeed, part of what made these products successful was the working relationships between farmers and researchers, which allowed for a more responsive approach; the presence of a market to purchase farmers' products, enabling them to generate profits, as well as to buy needed agricultural goods; and often private sector seed enterprises of various scales to support the availability of seed.

\section{Evolution and implications of separating resilience and profitability targets}

We began this paper by suggesting that ICRISAT has moved in the direction of a twin-track approach in which profitability and resilience are recognized as two distinct needs. Although this approach was introduced to help research achieve greater and faster impacts by focusing the attention to one specific target group and (or) problem, there are a number of potential problems inherent within it. So why the move in this direction? We suggest three explanations. First, many commodity CRPs want to see the commercialization of smallholder agriculture, viewing agricultural research as a business, farmers as consumers of new technology, and new technology as product lines targeted at different market segments. This is reinforced by the power of philanthrocapitalism-influential donors with a background in the private sector (Brooks 2013). Second, the review process for the two CRPs led by ICRISAT urged scientists to link new technology to two target groups, namely market-oriented farmers focused on profitability and subsistence-oriented farmers focused on resilience. This discouraged thinking about technologies that combined profitability and resilience and that cut across target groups. And finally, the nature of new technology is changing. Increasingly, new technology is diverging into two types of product lines: high-input product lines based on hybrid seed and intensive, knowledge-based management, which are designed for market-oriented farmers; and low-input product lines based on openpollinated varieties and lower levels of management, which are designed for subsistence-oriented farmers. This divergence reflects, at least in part, supply and demand. On the supply side, hybrid seed means that the private sector now sees commercial opportunities in smallholder agriculture. 
On the demand side, farmers are more willing to invest in these high-input product lines because they see market opportunities.

The approach to product development adopted by the ICRISAT-led research programs has a number of implications for the likely future successes of its AR4D efforts. Going back to the conceptual model of the product development (Fig. 1) with which we started the paper, we can identify two archetypal impact pathways, as depicted in Fig. 5. The impact pathway for product lines targeted at marketoriented farmers is led by the private sector using inclusive business models to ensure market participation by smallholders. Where these product lines involve hybrid seed, the private sector has an incentive to invest. The exemplar here is hybrid pearl millet in India, where AR4D and marketing is led by private seed companies. For product lines involving hybrid seed, ICRISAT does not have a major development role. However, the danger with market-led impact pathways is that they are dominated by large-scale commercial farmers. Inclusive business models are needed to ensure that the benefits go to smallholders (Byerlee and Haggblade 2013). Inclusion is a major theme of research on value chains by another CRP focusing on Policies, Institutions and Markets.

Some product lines in the profitability category (such as self-pollinated crops) may not attract private investors. Also, where profitable product lines require new consumer products, such as ready-to-eat foods, there is a case for business incubators to develop these.

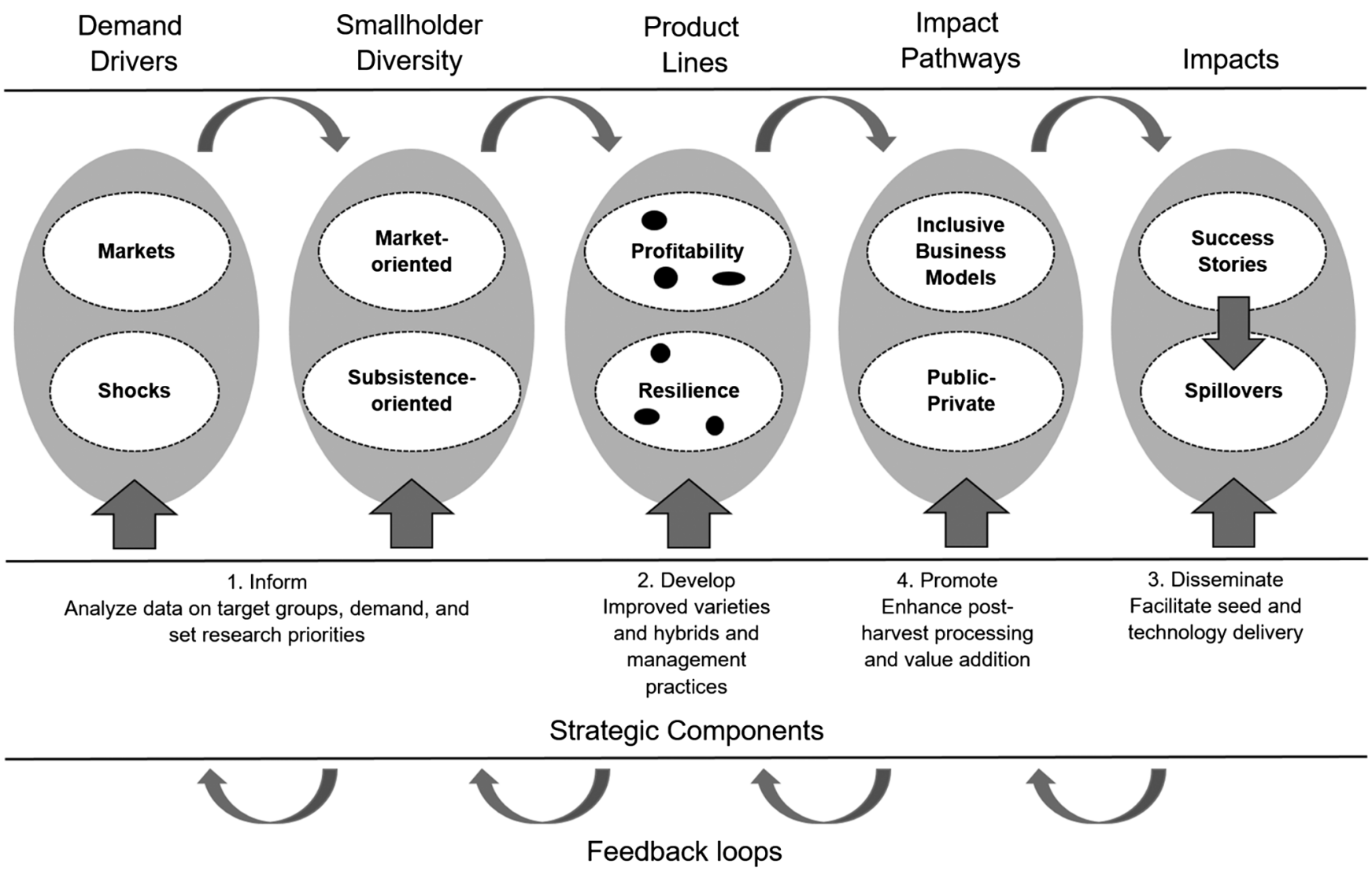

Fig. 5. Diagram of the process from product line design to impact. 
In contrast, the impact pathway for product lines targeted at subsistence-oriented farmers is led by a mix of stakeholders (from both public and private sectors). Public-sector agencies may have a greater development role, for example, in supplying seed. Historically, it has proved difficult to create effective and sustainable impact pathways for these product lines because, without the market incentives that attract private firms, success depends on cooperation among stakeholders that may have conflicting interests. Innovation platforms offer one possible approach. A successful example is the PanAfrican Bean Research Alliance that involves 28 countries (see ICRISAT et al. 2012). Finally, strategic component 3 facilitates feedback between research and stakeholders in the impact pathway, whereas strategic component 4 facilitates learning from successful and unsuccessful impacts. The aim of these feedback loops is to ensure that the research process remains interactive and driven by the needs of the end users. Ideally, the resulting impacts include both success stories in locations for which new technology was originally designed and spillovers where products are successfully transferred to other locations.

Product lines designed to improve profitability for market-oriented farmers require a dynamic private sector and suitable infrastructure. Where these conditions exist, as in India, spillovers from these product lines may be substantial. At present, however, these conditions are missing in some parts of Africa, which makes spillovers from India to Africa more difficult. For example, although there may be demand for sorghum hybrids in WCA, developing an impact pathway is problematic. Similarly, although there is potential demand for sweet sorghum for biofuels in Mozambique, the regulatory framework that exists in India and Brazil is not yet in place (Orr et al. 2013). These asymmetries will result in divergence between ICRISAT's regions, though as conditions in SSA improve over time, spillovers will become more likely. Consequently, although Africa needs profitable product lines, they will take longer to have impact. This suggests the need to assess the potential for spillovers by region. Indeed, this is one critical part of the process. The built-in feedback loops should inform researchers on how the technologies are used by farming communities and, by extension, how and where these uses could be applicable in other contexts and which supporting institutions and actors were involved to better facilitate spillovers. These supporting actors might be farmer organizations that help to disseminate the information or marketing groups that facilitate market linkages. They could also be facilitated by governmental policies like subsidy programs that enable exposure and learning by a large number of farmers.

\section{Conclusion}

Although it is too early to evaluate the successes or failures of the product lines stemming from the recent shift in ICRISAT's approach, the organization's experience shows that success can take various forms. Some success stories have increased resilience, others have increased profitability, and some have managed to increase both at the same time. At the same time, we have emphasized the interconnectedness of these two aims, leading to a number of potential problems when attempting to separate them too rigidly. First, the distinction between profitable and resilient product lines is difficult to reconcile with a systems approach, where the emphasis is not on making distinctions between individual product lines but on integrating product lines in ways that fit specific farming systems and environments. Although a twin-track approach to developing product lines may make sense for plant breeders, crop management scientists look for ways to increase resilience and profitability not of single components but of the system as a whole. This view is partially reflected in the win-win case studies in which farmers used a single target product within their system that evolved to be a win-win product. Similar examples are found elsewhere. The African Highlands Initiative in eastern Africa used profitable product lines that gave immediate financial returns as entry points in combination with resilient product lines with slower benefits. Thus, forage grasses immediately raised milk yields, whereas building terraces to conserve soil fertility gave longer term returns (German et al. 2012). 
Here, profitable and resilient product lines played complementary roles, resulting in a win-win package of innovations that gave both higher cash income and improved soil conservation for a specific farming system.

Another difficulty with the distinction between profitability and resilience in the development of product lines is the matching of product lines to specific target groups. At the household level, farmers need to combine both profitability and resilience. Subsistence-oriented farmers require profitable crops or livestock to provide cash income, whereas market-oriented farmers require resilient crops that give them food security. Similarly, farm households in transition from subsistence- to marketoriented farming may use profitable product lines to earn cash income that is then invested in strengthening resilience. Thus, different types of product lines can be used in sequence as part of the transition of smallholder farmers from subsistence agriculture to commercial and profitable enterprises. Many questions about this transition process remain open.

Finally, as the research focus shifts to the needs and priorities of more profit oriented, higher socioeconomic status farmers who are able to better utilize the profit increasing technologies the needs and priorities of subsistence-oriented farmers, who also tend to occupy the lowest socio-economic status within their communities and countries, may be overlooked. The majority of smallholder farmers own less than 2 ha of land (Hazell and Rahman 2013), ${ }^{11}$ but they differ in their degree of orientation to markets or to home consumption. Subsistence- and market-oriented farmers have different technology needs because they have different production objectives. Technology for subsistence farmers has to meet the needs of poor, hungry, and risk-averse smallholder farmers. It should improve household food security, stabilize yields, reduce risks, and require little additional cash. These farmers are more likely to want new technology that increases resilience. In contrast, market-oriented farmers have more resources, are less risk averse, and typically have better access to new technology and information. These farmers are more likely to want new technology that increases profitability.

For these reasons, we argue that it is important to recognize and incorporate smallholder diversity in the research process, and this includes a focus not only on different kinds of households but also on gender. Although not the focus of this paper, gender dynamics intersect with the distinction between the two target groups, with women tending to be more subsistence-oriented and men more marketoriented. The identification of the drivers and the impacts of commercialization on women could greatly enhance targeting and product development. Likewise, technology development and targeting efforts could be improved by recognizing and incorporating diversity into all stages of the work done by the CGIAR broadly and ICRISAT specifically.

The distinction of profitability and resilience has received a mixed reception from ICRISAT scientists. We need to test their implementation and resulting technologies in specific contexts to improve them and if necessary replace them as the CRPs evolve. Questions that remain to be addressed include whether clear targeting of profitable product lines for market-oriented farmers and the resilience product lines for subsistence farmers increase impacts. In addition, different types of product lines require different development partners. Do ICRISAT and the CRPs have the right partnership networks in place to facilitate this process? Moving forward, it is important that these questions be fully addressed to ensure not only that agricultural research is responsive to smallholder farmers' needs but also that research is able to target changes in global food demands.

\footnotetext{
${ }^{11}$ By this definition, India has 93 million small farms and Africa has 33 million small farms, representing approximately $80 \%$ of all farms in each region (O Nagayets, unpublished data, 2005).
} 


\section{Acknowledgements}

We thank the ICRISAT scientists at the annual Social Scientists' meeting who suggested an outline of contents. Tilahun Amede, Deevi Kumara Charyulu, Sabine Homann Kee-Tui, Uttam Kumar Deb, Romeo Mensah, Nareppa Nagaraj, Swamikannu Neduraman, Jupiter Ndjeunga, K.P.C. Rao, P. Parthasarthy Rao, Tom van Mourik, and Andre van Rooyen provided materials. Dave Harris, Sabine Homann Kee-Tui, and Eva Weltzien gave useful comments on a previous draft. The paper was edited by Swathi Sridharan. We thank Dave Harris and Anthony Whitbread, who reviewed the original working paper for ICRISAT. The authors are responsible for remaining errors and omissions, and for the views expressed in this paper that should not be attributed to the organization with which they are affiliated.

\section{Author contributions}

Conceived and designed the study: KM, AO. Performed the experiments/collected the data: KM, AO. Analyzed and interpreted the data: KM, AO. Contributed resources: KM, AO, BPM. Drafted or revised the manuscript: $\mathrm{KM}, \mathrm{AO}, \mathrm{BPM}$.

\section{Competing interests}

The authors have declared that no competing interests exist.

\section{Data accessibility statement}

All relevant data are within the paper.

\section{References}

Alinovi L, D’Errico M, Mane E, and Romano D. 2010. Livelihood strategies and household resilience to food insecurity: an empirical analysis to Kenya. In Paper prepared for Conference on Promoting Resilience through Social Protection in Sub-Saharan Africa, Dakar, Senegal, 28-30 June 2010. European Report on Development, Brussels, Belgium. 52 p. [online]: Available from europa.eu/ capacity4dev/hunger-foodsecurity-nutrition/document/livelihoods-strategies-and-household-resiliencefood-insecurity-empirical-analysis-kenya.

Bantilan MCS, Kumara Charyulu D, Gaur PM, Shyam Moses D, and Davis J. 2014. Short duration chickpea technology: enabling legumes revolution in Andhra Pradesh, India. ICRISAT Research Program on Markets, Institutions and Policies, Research Report No. 23, ICRISAT, Patancheru, India. [online]: Available from grainlegumes.cgiar.org/wp-content/uploads/2015/07/ J2014-100-Research-Report-No.23.pdf.

Brooks S. 2013. Investing in food security? Philanthrocapitalism, biotechnology and development. Science and Technology Policy Research Working Paper Series No. 12. University of Sussex, Brighton, UK.

Byerlee D, and Haggblade S. 2013. African food systems to 2030: toward inclusive business models. In Frontiers in food policy: perspectives on sub-Saharan Africa. Edited by WP Falcon and RL Naylor. From the Stanford Symposium Series on Global Food Policy and Food Security in the 21st Century held by the Center on Food Security and the Environment, Stanford, California. CreateSpace Independent Publishing, Palo Alto, California. pp. 505-540.

Chandy L, and Gertz G. 2011. Poverty in numbers: the changing state of world poverty from 2005 to 2015. Policy Brief 2011-1. The Brookings Institution, Washington, DC. 
Department for International Development (DFID). 2007. From research to innovation systems: Learning from the renewable natural resources strategy [online]: Available from gov.uk/dfid-research-outputs/from-research-to-innovation-systems-learning-from-the-renewablenatural-resources-research-strategy.

German L, Mowo J, Amede T, and Masuki K (eds.). 2012. Integrated natural resource management in the highlands of eastern Africa: from concept to practice. Earthscan, London, UK.

Harris D, and Orr A. 2014. Is rainfed agriculture really a pathway from poverty? Agricultural Systems, 123: 84-96. doi:10.1016/j.agsy.2013.09.005.

Hazell P, and Rahman A (eds.). 2013. New directions for smallholder agriculture. Oxford University Press, Oxford, UK.

ICRISAT. 2012. The jewels of ICRISAT. International Crops Research Institute for the Semi-Arid Tropics (ICRISAT), Patancheru, India. 68 p. [online]: Available from icrisat.org/jewels/ The-Jewels-of-ICRISAT.pdf.

ICRISAT and ICARDA. 2012. CGIAR Research Program on dryland cereals. A global alliance for improving food security, nutrition and economic growth for the world's most vulnerable poor [online]: Available from icrisat.org/crp/CRP3.6_Dryland_Cereals_15Aug12.pdf.

ICRISAT, CIAT, ICARDA, and IITA. 2012. CGIAR Research Program on grain legumes. Leveraging legumes to combat poverty, hunger, malnutrition and environmental degradation [online]: Available from icrisat.org/crp/CRP3.5_Grain_Legumes_15Aug12.pdf.

Kharas H. 2010. The emerging middle class in developing countries. Working Paper No. 285. OECD Development Centre, Boulogne Billancourt, France.

Mubila M, and Aissa MB. 2011. The middle of the pyramid: dynamics of the middle class in Africa. Market Brief, 20 April. African Development Bank (AfDB), Abidjan, Cote d'Ivoire. 24 p. [online]: Available from afdb.org/fileadmin/uploads/afdb/Documents/Publications/The\%20Middle\%20of\% 20the\%20Pyramid_The\%20Middle\%20of\%20the\%20Pyramid.pdf.

Orr A, and Mausch K. 2014. How can we make smallholder agriculture in the semi-arid tropics more profitable and resilient? A research perspective from ICRISAT-led CGIAR Research Programs. Working Paper Series No. 59. International Crops Research Institute for the Semi-Arid Tropics, Patancheru, India. 32 p. [online]: Available from oar.icrisat.org/8623/.

Orr A, Tsusaka T, Mgonja M, and Audi P. 2013. Sorghum scoping study, Mozambique. International Crops Research Institute for the Semi-Arid Tropics, Nairobi, Kenya. 48 p.

United Nations (UN). 2012. World population prospects: the 2012 revision. United Nations, Department of Economic and Social Affairs, New York, New York. [online]: Available from esa.un. org/unpd/wpp/Demographic-Profiles/index.shtm.

van Ginkel T, Sayer J, Sinclair F, Aw-Hassan A, Bossio D, Craufurd P, et al. 2013. An integrated agro-ecosystem and livelihood systems approach for the poor and vulnerable in dry areas. Food Security, 5(6): 751-767. doi:10.1007/s12571-013-0305-5.

Walker B, Carpenter S, Anderies J, Abel N, Cumming GS, Janssen M, et al. 2002. Resilience management in social-ecological systems: a working hypothesis for a participatory approach. Conservation Ecology, 6(1): 14. doi:10.5751/ES-00356-060114. 